Proceedings of the International Conference in Dubrovnik, 15-16 October 2015

\title{
STUDY OF THE FIRE PERFORMANCE OF HYBRID STEEL-TIMBER CONNECTIONS WITH FULL-SCALE TESTS AND FINITE ELEMENT MODELLING
}

\author{
Aaron O. Akotuah, Sabah G. Ali, Jeffrey Erochko, Xia Zhang, George V. Hadjisophocleous \\ Carleton University, Department of Civil and Environmental Engineering, Ottawa, Canada
}

\begin{abstract}
Connection design is critical in timber buildings since the connections tend to have lower strength than the structural members themselves and they tend to fail in a brittle manner. The effect of connection geometry on the fire performance of a hybrid steel-timber shear connection is investigated by full-scale testing. These tests were conducted by exposing the test specimens to the standard time-temperature curve defined by CAN/ULC-S101 (CAN/ULC-S101, 2007). Test results showed that the fire resistance of these connections depends on the load ratio, the type of connection and the relative exposure of the steel plate to fire. Finite element models of the connections under fire were constructed using ABAQUS/CAE and these were validated using the test results. These numerical model results correlate well with test results with $\pm 8.32 \%$ variation.
\end{abstract}

Keywords: timber connections, hybrid, fire resistance, full-scale testing, numerical model

\section{INTRODUCTION}

In building construction, wood is used in one of two ways: as a light-frame construction or as a heavy-timber construction. The use of wood in bigger and taller buildings necessitates a heavytimber construction approach where wood is used in combination with other building materials such as concrete and steel. This type of construction system is called a hybrid building system and is currently being considered for the construction of mid-rise wood buildings.

The metal components at timber connections are highly susceptible to fire, hence timber connections have been identified as a weak link in heavy timber construction with regards to fire safety. In building code design, if fire resistance is required, then codes typically require that connections must have the same fire resistance rating as the connected members. For the fire resistance design of typical heavy timber connections, the NBC (NBC, 2005) provides design guidance including the minimum thickness of the connected timber, spacing between fasteners and spacing between rows and columns of fasteners; however, detailed information or calculation of the fire resistance for hybrid timber-steel connections is not provided. There is no guidance related to the design or selection of hybrid connections provided in the NBC or any other Canadian document. This study investigates the effect of various design parameters on the fire performance of hybrid connections using full-scale tests and finite element models.

\section{DESCRIPTION OF EXPERIMENTS AND TEST SPECIMENS}

A series of fire-resistance tests was conducted in a furnace to study the influence of various parameters governing the fire performance of hybrid connections. The test assembly consisted of two pin-pin steel columns (W150x37) which were $3200 \mathrm{~mm}$ in height and a glulam beam 140x191 $\mathrm{mm}$ that was $1900 \mathrm{~mm}$ long. The beam was loaded using two point loads at $1 / 3$ points along its span. The steel columns were fully protected while only the top surface of the wood beam was protected to simulate the presence of the floor. A 3/8” shear tab plate with 4-A307 bolts was used to connect the beam to the steel frame. Figures 1 and 2 show the specimen in the furnace before and after testing. 


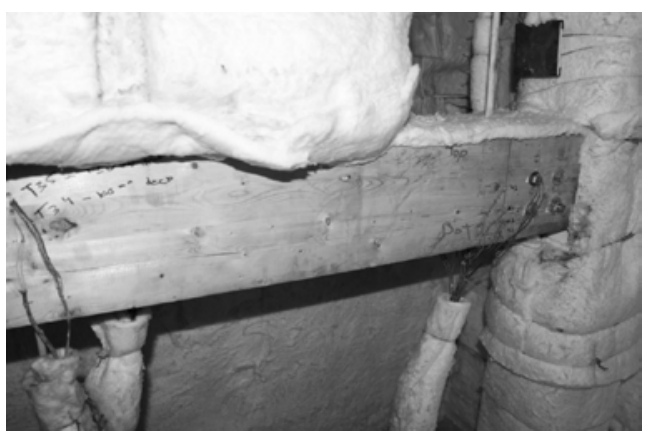

Fig. 1 Specimen placed in furnace

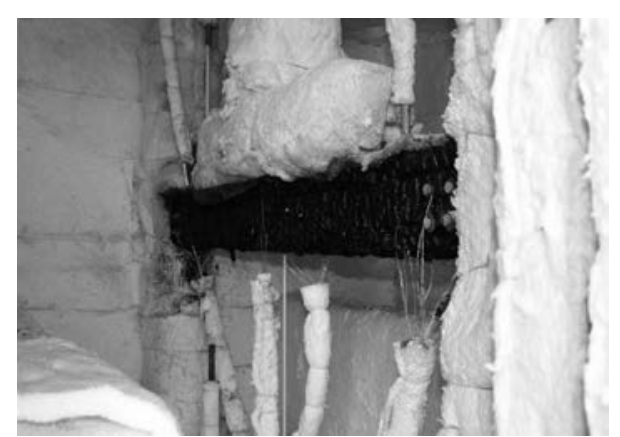

Fig. 2 Specimen in furnace after the test

The parameters considered in the tests include the type of connection, the load ratio and the bolt diameter. The experimental investigation considered the effect of steel plate exposure to fire, hence two different connection configurations; a concealed shear tab connection $(\mathrm{CN})$ and an exposed shear tab connection (EX) were tested (see Figure 3). The load ratio is the ratio of the applied constant vertical load on the beam during the test to its ultimate load-carrying capacity in ambient conditions. The load ratio applied on a structural member during a fire test can have a significant effect on its fire resistance. The standard CAN/ULC-S101 (CAN/ULC-S101, 2007) recommends that the specimen be subjected to a load that is as close as possible to its factored resistance, which is determined in accordance with the design standard published by the Canadian Standards Association (CAN/CSA O86-09, 2009) for timber connections. The fire standard also allows lower loads to be used in fire-resistance tests provided that the load conditions are identified and reported. In this study, the load ratio ranged from $30 \%$ to $100 \%$. Two different bolt diameters of $12.7 \mathrm{~mm}$ $(1 / 2 ")$ and $19.1 \mathrm{~mm}(3 / 4 ")$ were used in the experiments.
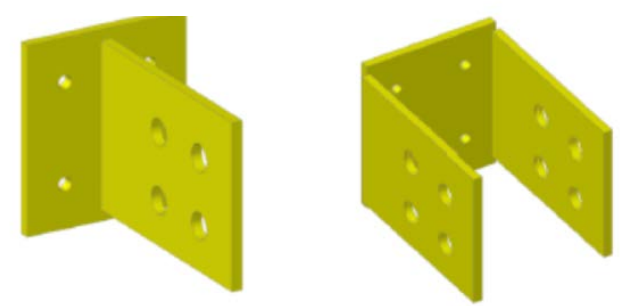

Fig. 3 Types of connections considered: (a) Concealed (CN) (b) Exposed (EX)

\subsection{Test procedure}

The steel columns were connected to the external steel loading structure that surrounds the furnace. Each column was restrained at its top and bottom against the in-plane and out-of-plane lateral movements. The top and bottom ends of the columns were rotationally unrestrained to avoid the development of unnecessary moments in the steel loading structure. After installing the steel-frame test assembly inside the furnace, the test beam was subjected to a constant vertical loading before and during the fire-resistance test. This load was applied as two point loads which were $700 \mathrm{~mm}$ apart. This load was maintained for a minimum of 20 minutes and then the test assembly was subjected to gradually increasing temperatures that followed the CAN/ULC-S101standard timetemperature curve (CAN/ULC-S101, 2007) until failure. The furnace temperatures were regulated during the test to follow the CAN/ULC-S101 standard time-temperature curve within $\pm 10 \%$.

\section{FINITE ELEMENT MODELLING}

To simulate the fire resistance test, the system was modelled and analysed using a sequentially coupled thermal-stress procedure in ABAQUS/CAE. This approach adopts a pure transient heat transfer model to determine the temperature distribution and history on the assembly followed by a 
static structural analysis at each time step of the heat transfer to determine the mechanical response of the structure.

The individual components of the assembly were meshed separately in order to account for the difference in geometrical size and shape. Curved sections on the bolt and bolt-hole areas on the beam, column and plate were meshed with fine meshes which can simulate closely the actual geometry in the test setup. These are important regions where results are transferred between individual members through contact algorithms during the simulation. Other regions were meshed with relatively coarser meshes (see Fig. 4). Welded regions of the plate sections were also modelled as monolithic with the adjoining parts. Other parts such as bolts, nuts and washers were lumped together in order to reduce the numerous contact regions in the model.

Three-dimensional diffusive solid elements (DC3D8) in ABAQUS (ABAQUS/CAE, 2011) were used to define all components of the assembly for the heat transfer analysis. Temperature-dependent thermal properties of thermal conductivity, density and specific heat capacity were assigned to each element to calculate the heat conduction within the model assembly. The temperature-dependence of the thermal parameters were derived by using reduction factors obtained from literature (Eurocode 5, 2004; Eurocode 3, 2001). Charred sections of wood provide a partial insulation which reduces heat penetration in the wood. Charring of wood continues until minor cracks are formed in the wood section (due to expansion) and this on the contrary increases the conductivity. This pyrolysis property of the wood is factored in the temperature-dependence of the wood conductivity value. Heat transfer between discontinuous contacting surfaces of the assembly was modelled using the gap conductance feature. Heat transfer to the boundary surfaces of the assembly was modelled by supplying an appropriate heat flux to the exposed sides using a DFLUX user subroutine (Peng L. et al., 2012) in ABAQUS (ABAQUS/CAE, 2011). The heat flux to the boundary incorporates both the convective and radiation components of the heat from the furnace. The average timetemperature data that was recorded during the test $\left(T_{f}\right)$ was used to estimate the heat flux to the boundary according to equation (1).

where:

$$
\dot{q}^{\prime \prime}=h_{c}\left(T_{f}-T_{s}\right)+\varphi \varepsilon_{f f} \sigma\left(T_{f}^{4}-T_{s}^{4}\right)
$$

$$
\begin{aligned}
& h_{c}=\text { convection coefficient } \quad T_{f}=\text { furnace temperature } \\
& T_{s}=\text { surface temperature of assembly } \varphi=\text { configuration factor } \\
& \varepsilon_{f f}=\text { effective emissivity } \sigma=\text { Stefan }- \text { Boltzman constant, } 5.67 \times 10^{8} \mathrm{~W} / \mathrm{m}^{2} \mathrm{~K}^{4}
\end{aligned}
$$

To simulate the structural response of the model, a nonlinear static analysis of the structure was conducted in two stages. First, the full load ratio was applied in increments. Then, the heat from the fire to the assembly was applied while the first stage load remained constant. Three-dimensional continuum elements (C3D8R) in ABAQUS were used to define all components of the assembly. Temperature-dependent Isotropic and Orthotropic elastic properties were assigned to the steel and wood parts respectively. The temperature-dependent elastic properties consider the softening of the material due to heat penetration through reduction factors as outlined in literature (Buchanan A. H., 2002; Eurocode 5, 20 04, Eurocode 3,2001 ). The brittle nature of wood, which is further compounded due to charring, was also simulated by employing the Linear Fracture Mechanics (LEFM) approach in the wood material model.

The contact simulation in the model was implemented through the tangential and normal properties, which were assigned to the contacting surfaces. The tangential behaviour was defined by a friction coefficient of 0.3, which is typical of wood-metal surface interactions (ASM Handbook, 1992). The normal behaviour between the contacting surfaces was defined as a "hard contact" in Abaqus. A "hard contact" is based on the principle that stresses can be transferred between surfaces at zero clearance and no stresses are transferred when the surfaces are not in contact. All contact pairs and their respective contact properties were defined before the start of the numerical analysis in order to simulate the initial conditions of the assembled test specimen at the beginning of the experiment. 
Only half of the full assembly was modelled in ABAQUS due to symmetry (see Fig. 4).

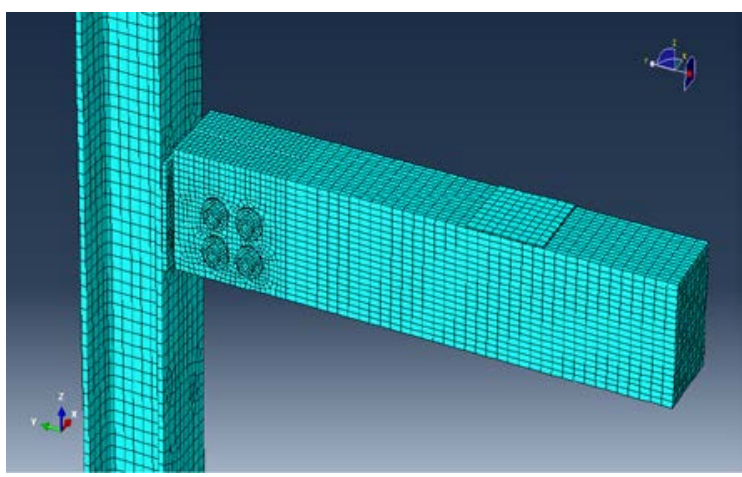

Fig. 4 Meshed model in ABAQUS

\section{RESULTS AND DISCUSSION}

\subsection{Fire Resistance (Failure Time)}

Table 1 summarizes the test and model results including the actual failure time and the predicted failure time based on the model. The model predicted the failure time with an average variation of $\pm 8.32 \%$.

Table 1 Test description and failure times

\begin{tabular}{|c|c|c|c|c|c|c|c|c|}
\hline Plate & $\begin{array}{c}\text { No. of } \\
\text { Bolts }\end{array}$ & $\begin{array}{c}\text { Bolt } \\
\text { Dia. } \\
(\mathbf{m m})\end{array}$ & $\begin{array}{c}\text { Plate } \\
\text { Thickness } \\
\mathbf{( m m})\end{array}$ & $\begin{array}{c}\text { Load } \\
\text { ratio } \\
\mathbf{( \% )}\end{array}$ & $\begin{array}{c}\text { Failure } \\
\text { Time } \\
(\mathbf{m i n s})\end{array}$ & $\begin{array}{c}\text { Model } \\
\text { predicted } \\
\text { time (mins) }\end{array}$ & $\begin{array}{c}\text { Variation } \\
\mathbf{( \% )}\end{array}$ & Failure Mode \\
\hline CN & 4 & 19.1 & 9.5 & 30 & 35 & 34.7 & -0.86 & Wood splitting \\
\hline CN & 4 & 19.1 & 9.5 & 100 & 15 & 13 & -13.3 & Wood splitting \\
\hline CN & 4 & 19.1 & 4 & 30 & - & 13 & - & Plate buckling \\
\hline EX & 4 & 19.1 & 9.5 & 30 & - & 40.7 & - & Wood splitting \\
\hline EX & 4 & 19.1 & 9.5 & 60 & 25 & 27.7 & +10.8 & Wood splitting \\
\hline EX & 4 & 19.1 & 4 & 30 & - & 39.6 & - & Wood splitting \\
\hline
\end{tabular}

The load ratio on the connection assembly and the relative exposure of the wood and steel sections to fire are among the factors which influence the connection's fire resistance. Table 1 shows that increasing the load ratio on a particular connection assembly reduces its fire resistance since the highly stressed connection members degrade quickly in strength under fire conditions. With other parameters held constant, the EX connection performs slightly better than the $\mathrm{CN}$ connection. This is attributed to the difference in direct exposure of the wood to fire at the connection. As it will be realised later in the charring rate observation, the outer plates provide some brief partial protection to the EX connection unlike the $\mathrm{CN}$ connection which has an increase in heat transfer directly to the wood core via the steel plate. The increase in charring at the $\mathrm{CN}$ connection hence reduces its fire resistance as compared to the EX connection.

Further analysis with the finite element model shows that reducing the thickness of the outer plate to $4 \mathrm{~mm}$ in the EX connection seems to have an insignificant bearing on the fire resistance (see Table 1) since the structural capacity of the steel plate is not affected. However, reducing the plate thickness of the $\mathrm{CN}$ connection results in a significant reduction in its fire resistance to 13 minutes since buckling failure in the steel plate occurs. The predominant failure mode in the tests was the splitting of wood parallel to grain and this was noticed in both the test and the numerical model. These splits originated at the bolt-hole edges, which are regions of high stress concentration. Under loading, the bolt shank transfers compressive stresses to the wood below, which acts as a wedge imposing lateral stresses parallel to grain to form cracks. Once the localized crack at the connection level is formed, it propagates along the beam and eventually leads to splitting failure. This failure mode is shown for the test and model in Figure 5. 


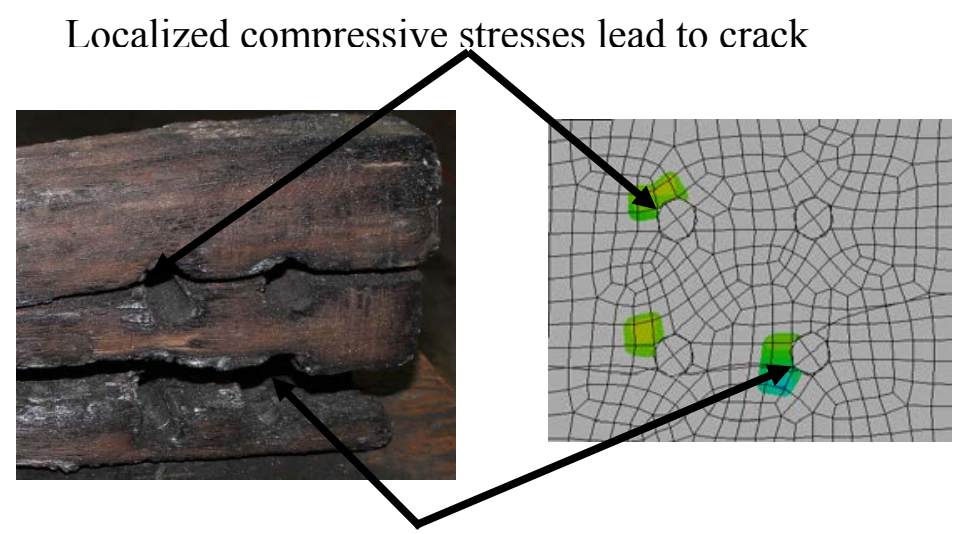

Wedge action from compressed wood leads to splitting failure

Fig. 5 Failure around bolt connection

\subsection{Charring Rate}

Figure 6 shows a temperature contour on a cross-section at the beam midspan from ABAQUS alongside a picture of a charred section from the test. An average surrounding thickness of $28 \mathrm{~mm}$ lies within the charring temperature region as obtained from the model. This leaves a r esidual section of about $84 \mathrm{~mm}$ from the model as opposed to $85 \mathrm{~mm}$ from the test. Table 2 below is a summary of the average charring rate obtained from both the test and the numerical model which is within $\pm 14 \%$ from the common standard charring rate of wood (Buchanan A.H., 2001). The table also shows that the charring rate at the connection was reduced to $0.56 \mathrm{~mm} / \mathrm{min}$ for the EX test which can be attributed to the brief partial protection that the steel plates provide to the wood behind them, therefore delaying its charring. The charring at the connection locations is strongly influenced by the bolts and steel plates. For a typical concealed plate connection, the bottom of the plate is subjected to heat flux which transfers heat directly to the center of the beam cross-section, hence increasing the charring rate there. In Figure 7, the influence of the bolt on the charring rate is seen as a further reduction of the residual cross section. This results in an average charred layer of $33 \mathrm{~mm}$ and a corresponding charring rate of $0.94 \mathrm{~mm} / \mathrm{min}$.

Table 2 Charring rate

\begin{tabular}{|l|c|c|c|c|c|}
\hline & $\begin{array}{c}\text { Beam } \\
\text { Center }(\mathbf{C N} \\
\text { and EX) }\end{array}$ & $\begin{array}{c}\text { CN at } \\
\text { connection }\end{array}$ & $\begin{array}{c}\text { EX at } \\
\text { connection }\end{array}$ & Model & $\begin{array}{c}\text { Average } \\
\text { charring rate } \\
\text { of Glulam }\end{array}$ \\
\hline Charred layer $(\mathrm{mm})$ & 27.5 & 33 & 14 & 28 & - \\
\hline Charring rate $(\mathrm{mm} / \mathrm{min})$ & 0.78 & 0.94 & 0.56 & 0.8 & 0.7 \\
\hline
\end{tabular}

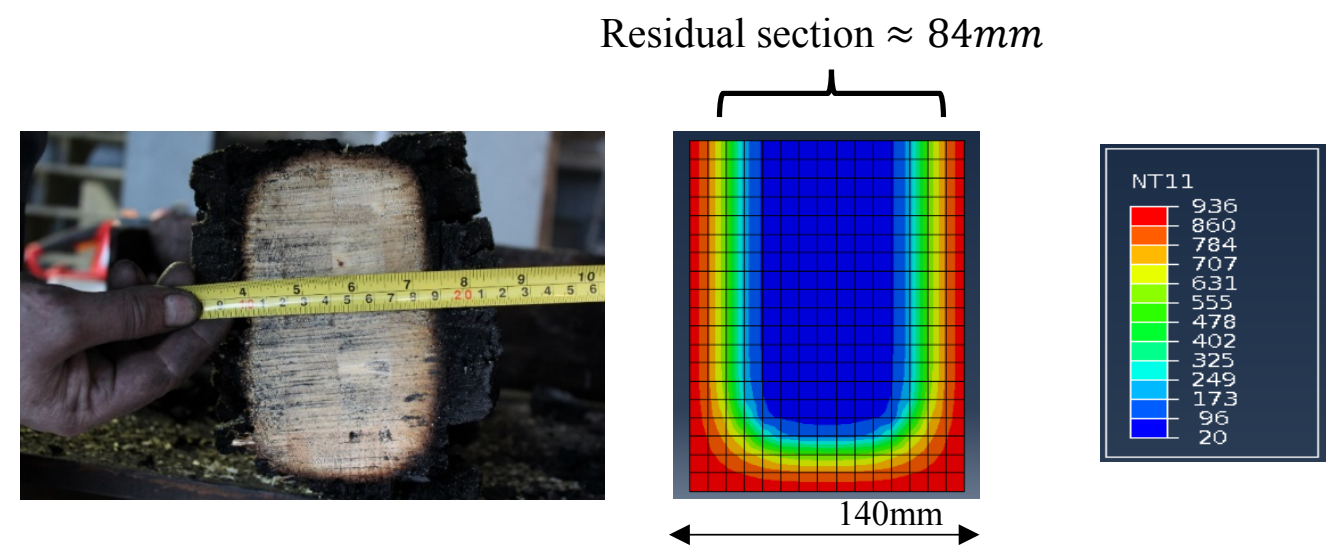

Fig. 6 Typical middle charred section after 35 minutes 


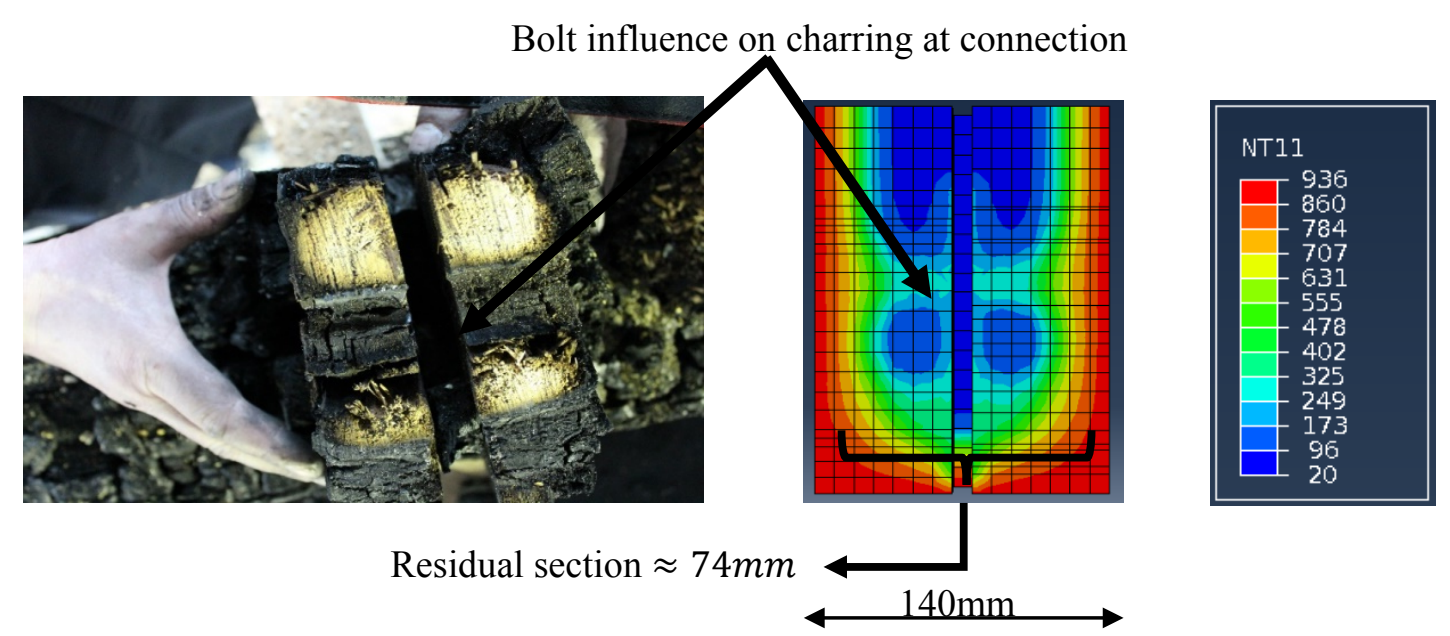

Fig. 7 Typical charred section at the connection after 35minutes

\section{CONCLUSIONS}

An investigation of the fire resistance of a hybrid steel-timber connection shows that the assembly's fire performance depends on the amount of load present on it during fire conditions. Increasing the load ratio reduces the fire resistance of the connection. It is also observed from both the full-scale tests and numerical models that the relative exposure of the steel sections (bolts and plates) and the wood to fire determines the rate of degradation of the connection's strength. Wood chars at the connection when heat is applied and this initiates brittle failure (splitting of the wood), propagation of cracks which eventually leads to ultimate failure of the assembly. This observation was made in both the experiments and the models and used as an estimation of the connection's fire resistance. The failure time predicted by the model was within $\pm 8.32 \%$ of the test results. Due to the high conductivity of the steel sections, charring of wood at the connection regions was higher compared to other regions of the wooden beam. The charring rate of the $\mathrm{CN}$ connection $(0.94 \mathrm{~mm} / \mathrm{min})$ was observed to be higher due to the direct exposure of wood to fire and the transfer of heat through the plate directly to the wood core. The EX connection on the other hand recorded a lower charring rate $(0.56 \mathrm{~mm} / \mathrm{min})$ due to the brief partial protection provided by the exposed plates to the wood behind.

\section{REFERENCES}

ABAQUS/CAE Version 6.11 Standard Manual, 2011. Dassault Systemes, Rhode Island, US.

ASM Handbook (1992), "Friction, Lubrication, and Wear Technology", ASM International, Vol. 18 Buchanan A.H. Structural Design for Fire Safety, 2001. John Wiley \& Sons Ltd, Chichester, West Sussex, England.

CAN/ULC-S101. Standard methods of fire endurance tests of building construction and materials. 2007. Underwriter's Laboratories of Canada, Scarborough, Canada.

CAN/CSA-O86-09. Engineering Design in Wood CAN/CSA-O86-1. 2009. C anadian Standards Association, Rexdale, ON, Canada.

EN 1993-1-2 (2001), "Eurocode 3 - Design of Steel Structures. Part 1.2: General rules - Structural Fire Design"

EN 1995-1-1 (2004), "Eurocode 5 - Design of Timber Structures. Part 1-1: General-Common rules and rules for buildings". CEN/TC 250/SC5, 2004-11-01

Lei Peng, George Hadjisophocleous, Jim Mehaffey and Mohammad Mohammad, Fire Performance of Timber Connections, Part 1: Fire Resistance Tests of Bolted Wood-Steel-Wood and SteelWood-Steel Connections, Journal of Structural Fire Engineering, 2012. Vol 3, Number 2 pp. $107-132$

NBC. National Building Code of Canada in Canadian Commission on B uilding and Fire Code. 2005. National Research Council of Canada, Ottawa, ON, Canada. 